\begin{tabular}{|ccc}
\hline Sournals & $\begin{array}{c}\text { INTERNATIONAL JOURNAL OF } \\
\text { ORGANIZATIONAL LEADERSHIP }\end{array}$ & $\begin{array}{c}\text { INDUSTRIAL } \\
\text { MANAGEMENT } \\
\text { INSTITUTE }\end{array}$ \\
\hline \hline
\end{tabular}

\title{
Motivational drivers of competitive and cooperative personalities: Implications for efficient HR management
}

\author{
Vít Janiš $^{1 *}$, Pavel Žiaran² \\ ${ }^{1}$ Mendel University in Brno, Faculty of Business Economics, Zemědělská 1, 61300 Brno, Czechia \\ ${ }^{2}$ Newton College, Department of Social Sciences, Rašínova 103/2, 60200 Brno, Czechia
}

\begin{abstract}
Keywords:

HRM, Motivational

Factors, Competitive and

Cooperative Behavior,

Big Five Personality

Inventory

\section{Received}

29 September 2016

Received in revised form

16 December 2016

Accepted

17 December 2016

Correspondence:

vit@janisovi.cz

The aim of the current study is to analyze motivational drivers important for the competitive and for the cooperative personality types which may have relevant implications for HR management. Nowadays, corporations in their search for efficiency should enhance their talent management and focus on the most relevant motivational factors. Today, another significant aspect of a dynamic corporation refers to the need for people who are both greatly cooperative and reactive to competitive forces within the corporation. Our analysis is based on a data collected via online questionnaire survey. The sample $(\mathrm{N}=629)$ consists of Czech economically active population. Personality types (competitive and cooperative) are derived from the Neo (big five) personality inventory methodology. The study includes nine motivational factors such as financial reward, appreciation of work performance, stability of a job, potential for personal development, etc. Analytical methods used in the study include factor analysis, correlation analysis, and a three-dimensional graphical analysis - for better presentation of results and practical implications. The results correspond to the empirical expectations and at the same time bring an interesting insight which improves understanding of the psychological functioning of a personality as well as ways of efficient motivation of personnel in the corporate environment.
\end{abstract}

(C)AIMI Journals

\section{Introduction}

Understanding the nature of motivation of employees might be crucial for creating an efficient working environment. Companies focus their attention on development of models of competencies and motivational drivers to increase working efficiency of employees.

This paper is a continuation of effort to map and understand the nature of motivational drivers that have been introduced in previous research of authors (Žiaran, Janiš, \& Pánková, 2015), aimed to understand the underlying psychological structure of the motivational drivers; also, 
the paper is the continuation of another research where authors investigated the nature of competitive and cooperative personality traits (Kolařová \& Žiaran, 2016).

Intuitively, authors would expect that the personality traits-cooperativeness and competitiveness - are in their nature perceived as opposite. However, nowadays in organizations, there is a need to special type of people who are highly cooperative. On the other hand, there is a need for people who are highly responsive to competitive challenges that regard their own performance as well as the performance of the team, department or the whole organization. The aim of the research is to contribute to the improvement of HR management, especially motivation and talent management in organizations.

\section{The Literature Review}

\section{Model of Work Competencies and Motivations}

The model of work competencies can be defined as a collection of knowledge, experiences, skills, abilities, and other characteristics that are necessary for effective performance in work. The model of competencies can be understood as talent-based interpretation of business needs. This view explains competencies as clearly apparent characteristics of a person including knowledge, skills, and behaviors that enable performance. The main purpose of the competencies is to communicate with both inside and outside of the company to make it clear that what people must know and master to efficiently contribute to the business.

In the competence model of a professional manager, the competences are formulated as qualities useful for an efficient performance and personality development in given environment or organizational context. The competencies should be understood as behavioral frameworks and personality traits. These frameworks concern specific system, function, position, situation, or task. In this relation, it is possible to identify specific personality traits which generate the competences. These traits could be measured and evaluated in the frame of performance of an individual or a team (Ambrozová, Koleňák, Ullrich, \& Pokorný, 2016).

The competency-based model grows in an organization which wishes to outperform the competition thanks to the increase in knowledge and skills of its employees. This concerns the knowledge-based organizations where the increase in productivity is realized due to the new added value of the employees.

In this research, the authors use competencies based on personality traits as personality proves to be one of the most stable constructs in time and thus works as a good predictor of success at work. Personality is considered to be the most important factor for the work performance. Related work competence questionnaires have high predictive validity. Personality is equally a phenomenon that discerns well among the people and their qualities. However, the evident disadvantage of the self-report is a potential difference between the selfperception and the perception of others. That is why it is important to verify the results of such test in the frame of a personal interview. Table 1 shows the personality traits related to organizational behavior.

\section{Models of Motivational Drivers}

Work motivation can be defined as a set of forces that initiate, direct, and sustain behavior and also determine the intensity of that behavior (Pinder, 1998). Meyer, Becker, and Vandenberghe 
(2004) indicated the relation between the level of motivation and the intensity of attempt to accomplish a work task. There is a wider portfolio of motivational tools as leadership style, participation of employees in the decision-making process, training and development of their professional and personal potential, and system of rewards (Webb, Perry, \& Fennelly, 2015). In the presented research, a model consisting of nine values was used by Cut-e Company which is based on a motivational model built on three pillars, namely goals, relationship, and environmental factors. The model is based on empirical studies related to satisfaction at work and job involvement over the time (Steel \& Rentsch, 1997) and research of Meglino and Ravlin (1998) focused on describing values affecting organizations nowadays.

Table 1

Personality Traits Related to Organizational Behavior - Used in the Research

\begin{tabular}{ll}
\hline Competence & Definition \\
\hline Influence & Ability to influence others, to be understood, Approved, and supported \\
\hline Social self-esteem & Understands his or her own value in the society, good predispositions for networking \\
Sociable & Open for communication, extroverted, enjoys social events \\
\hline Cooperative & Prefers cooperative solutions \\
\hline Result-Oriented & Focused on solutions and activities with clear and well accomplished results \\
\hline Systematic & Prefers to plan and organize, prefers clear structures and well-defined priorities \\
Conscious & Respects the rules and processes \\
\hline Prudent/long-term focus & Prefers to think in the long-term horizon \\
Inventive & Enjoys and searches for the new approaches and solutions \\
\hline Autonomous & Prefers to act based on his or her own initiative \\
\hline Ambitious & Determined to achieve his or her goals \\
Competitive & Enjoys competitive environment and challenges \\
\hline
\end{tabular}

Note. Source: Authors

The model of values is constructed to reflect the current reality at given workplace and does not have the ambition to cover the whole range of possibilities. This reflects the requirement of Greenwald and Banaji (1995) of a value measurement system: A value system of an individual should be closely linked to current activities and behavioral options. Table 2 displays the motivational drivers and their description used in the research.

Table 2

Motivational Drivers and Their Description Used in the Research

\begin{tabular}{|c|c|}
\hline Motivational driver & Description \\
\hline Financial Reward & $\begin{array}{l}\text { Prefers performance-oriented or adequate pay; considers important that an extra work is extra } \\
\text { rewarded; is motivated by financial incentives }\end{array}$ \\
\hline Professional Challenge & personal competencies and skills, prefers working environment which stimulates continuous learning and thinking \\
\hline $\begin{array}{l}\text { Appreciation of Work } \\
\text { Performance }\end{array}$ & $\begin{array}{l}\text { Would like to receive personal recognition for special achievements; considers important that successful actions } \\
\text { are acknowledged and also accordingly appreciated }\end{array}$ \\
\hline Personal Development & $\begin{array}{l}\text { The company places a lot of importance on further personal and career development and offers good possibilities } \\
\text { for further training }\end{array}$ \\
\hline Need of Structure & $\begin{array}{l}\text { Rules and responsibilities are clearly arranged in the company; the working processes are determined by clear } \\
\text { regulations }\end{array}$ \\
\hline $\begin{array}{l}\text { Job Mission } \\
\text { Identification }\end{array}$ & People are proud of what they do and the work is not only seen as a job but also as meaningful and necessary \\
\hline Job Stability & The jobs in the company are relatively safe and people feel that they are taken care of \\
\hline Work Environment & $\begin{array}{l}\text { Prefers well equipped working environment, appreciates offices which are pleasant and functional at the same } \\
\text { time }\end{array}$ \\
\hline Need of support & $\begin{array}{l}\text { People support each other in order to finish tasks; people have the feeling that they work together and not against } \\
\text { each other }\end{array}$ \\
\hline
\end{tabular}

Note. Source: Authors 


\section{Research Questions}

The following research questions guided the study:

- Which motivational drivers relate to the competitive personality trait?

- Which motivational drivers relate to the cooperation personality trait?

\section{Method}

The objective of the research was to analyze the nature of the motivational drivers that are related to the competitive versus cooperative personality with implications in the HR selection processes and with a vision to optimize motivational system and talent management in companies. The current study is conceived as an empirical study. The data was analyzed $(\mathrm{N}=$ 629) containing information on personality traits and motivational factors. The authors employed combination of factor analysis (for personality traits), correlation analysis, and graphical analysis based on a three-dimensional picture (for the motivational factors) using the graphical method of negative exponential adjustment and linear method in some cases.

In the research part, a factor analysis is employed to analyze the position of cooperativeness and competitiveness in relation to other personality traits. Subsequently, a correlation analysis was used to investigate the relation between the personality traits and respective motivational drivers. Correlation analysis was followed by a graphical analysis of three-dimensional surface graphs to provide better understanding of the relation between personality traits and motivational drivers.

In the frame of the graphical analysis, except for the linear method, a negative exponentiallyweighted fitting (smoothing) procedure was employed. The procedure is based on a polynomial regression algorithm similar to the one used in the distance-weighted least squares procedure. Hence, the weights that govern the effect of individual data points on consecutive segments of the curve (depending on their distance from the given segment) are assessed according to a negative (decreasing) exponential function (Statistica 12 - User guide, 2016).

Following this, 629 participants ( $17 \%$ of females), age 20-50 from Czechia-central region and the capital-participated in the study. Tests were administered via standard internet survey. The survey consisted of two parts, namely personality traits and motivational drivers.

\section{Results}

Competitive personality trait data can be defined as follows: $\mathrm{n}=629$; average $=4.1765$; and standard deviation $=2.0602$. Cooperative personality trait data can be described as follows: $\mathrm{n}=$ 629 ; average $=5.2353$; standard deviation $=1.92$. Both variables generate statistically significant negative correlation (correl. coefficient $=-0.2190$, $\mathrm{p}$-value $=0.00$ ). Distribution of the data is displayed in Figure 1. 

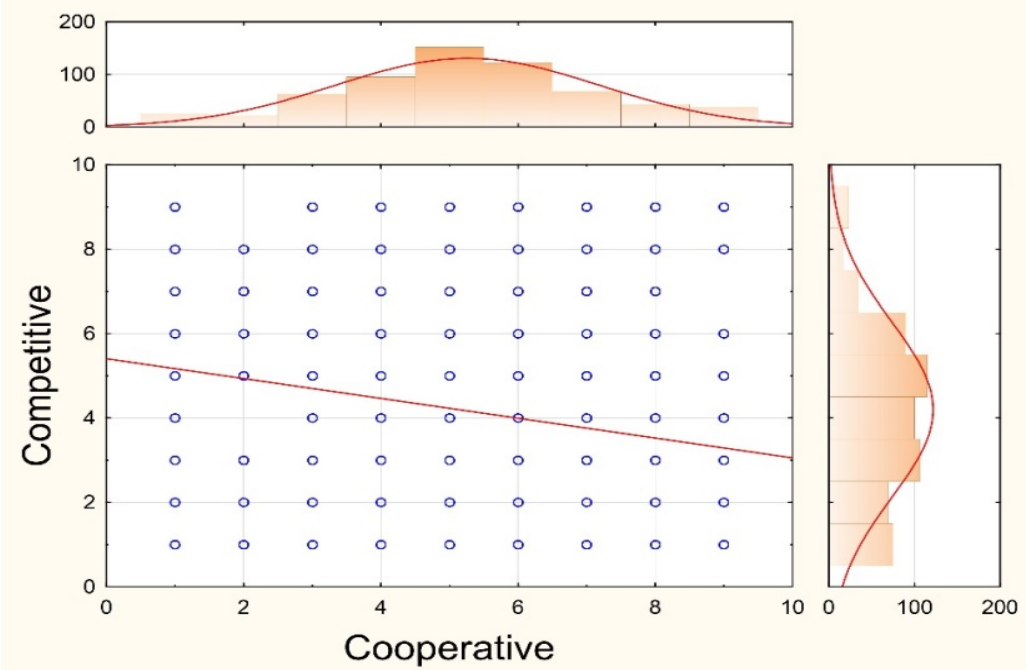

Figure 1. Motivational drivers and their description used in the research - distribution of the data Note. Source: Authors

Even if the data are not normally distributed, the data on both personality traits are sufficiently distributed along the scale; hence, a reasonable outcomes provided by the correlation analysis and other methods can be expected.

\section{Factor Analysis}

In order to understand the nature and position of both variables, in the position to other variables, the factor analysis was employed (using the method of principal component analysis, main axis method with rotation - simple varimax). There were two factors extracted (numbers 1.449 and 1.029) and the summary of factor charges is displayed in Table 3.

Table 3

Factor Analysis Competitive vs. Cooperative Environment

\begin{tabular}{lclc}
\hline & Factor 1 & & Factor 2 \\
\hline Ambitious & 0.61 & Sociable & 0.43 \\
Result Oriented & 0.50 & Self-Esteem & 0.32 \\
Resistant & 0.41 & Autonomous & 0.31 \\
Competitive & 0.33 & Inventive & 0.31 \\
Inventive & 0.31 & Socially Sensitive & 0.30 \\
Influential & 0.28 & Influential & 0.28 \\
Systematic & 0.24 & Competitive & 0.28 \\
Prudent & 0.23 & Prudent & 0.20 \\
Conscious & 0.09 & Ambitious & 0.10 \\
Sociable & 0.02 & Cooperative & 0.05 \\
Self-Esteem & -0.01 & Systematic & 0.02 \\
Autonomous & -0.03 & Resistant & -0.14 \\
Socially Sensitive & -0.16 & Result-Oriented & -0.19 \\
Open-Minded & -0.17 & Open-Minded & -0.19 \\
Cooperative & -0.40 & Conscious & -0.46 \\
\hline
\end{tabular}

Note.Source: Authors. The analysis uses the method of principal components- component analysis, main axis method with rotation- simple varimax), sorted according to the factor charges.

Table 3 shows that both variables lie at almost opposite sides of the spectrum (factor charges were 0.33 and -0.40 for competitive and cooperative personalities, respectively). When 
it comes to Factor 1, competitiveness is surrounded by the traits as resistance and result orientation on one side and by the traits as inventiveness, influence, and systematism on the other side. Cooperativeness is near to social sensitiveness and open-mindedness.

When sorted according to the Factor 2, both variables lie near, at the same side of the spectrum (factor charges were 0.28 and 0.05 for competitive and cooperative variables). For better empirical understanding of the differences between the cooperative and competitive traits and their interrelation with other personality traits, the graph of factor charges is presented in Figure 2.

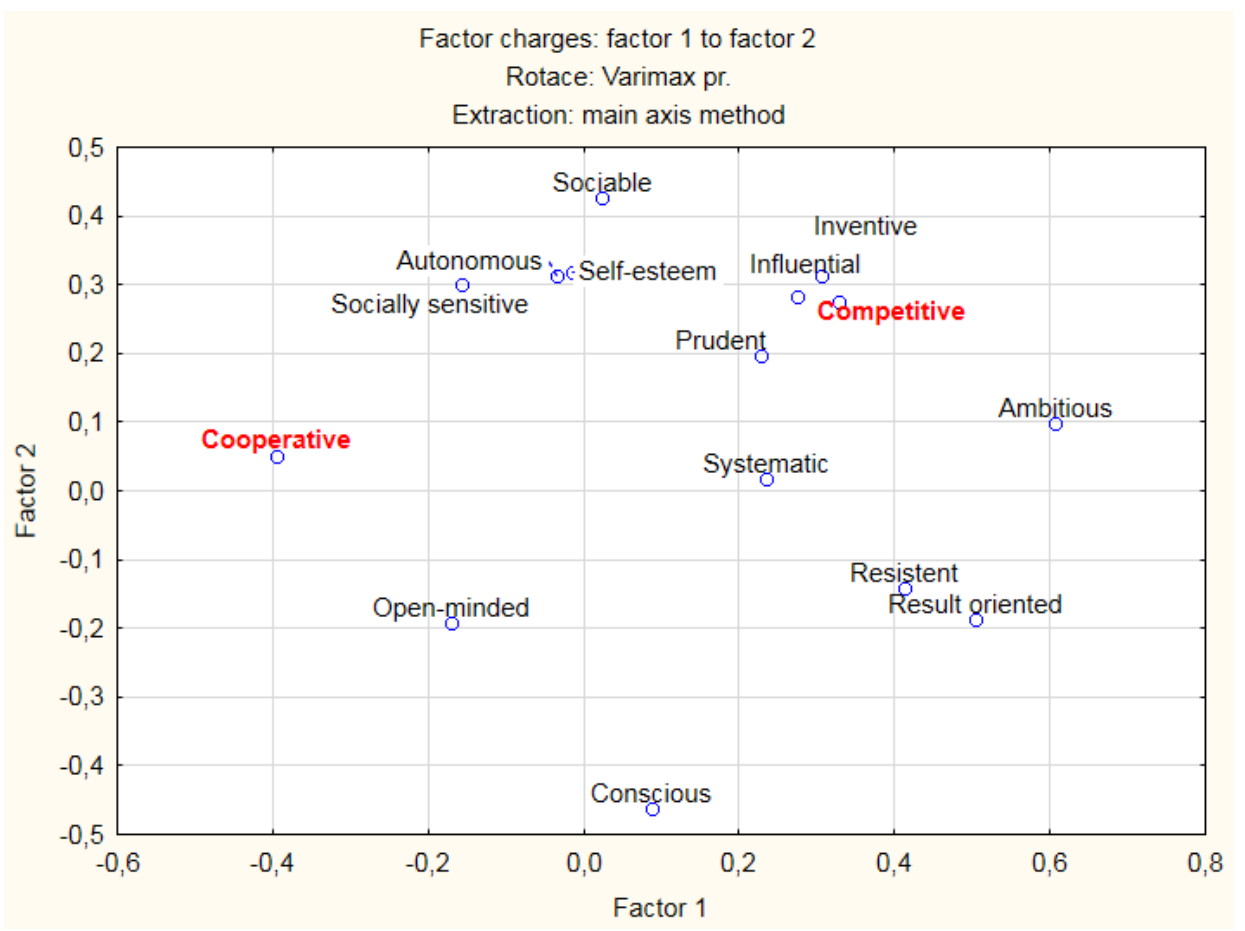

Figure 2.Factor analysis competitive vs. cooperative environment

Note. Source: Authors. The analysis uses the method of principal component analysis, main axis method with rotation- simple varimax

Figure 2 shows that cooperative behavior is to a large extent isolated from the other behavioral traits, so it can be assumed it is a self-standing trait having rather specific nature. On the other hand, the competitive trait finds itself close to the traits as influence or inventiveness or prudence eventually.

\section{Correlation Analysis}

With the aim to provide a good understanding of the nature of motivational drivers, the correlation analysis was employed (using Pearson coefficient) between both personality traits and the set of nine motivational drivers and the correlation matrix is shown in Table 4. Correlation coefficients marked by asterisk are statistically significant ( $p$-value $>0.05$ ).

At the top of the Table 4, there are motivational drivers which create positive correlation with competitive personality traits and negative correlation with the cooperativeness and vice-versa at the bottom of the Table 4. Consequently, the nine motivational factors can be divided into three categories as follows: first category refers to motivational drivers with positive 
correlation to the competitive and negative correlation to the cooperative personality traits including financial reward, professional challenge, and appreciation of work performance. Second category considers motivational drivers with statistically insignificant or negative correlation to the both personality traits, namely personal development, need of structure, and job mission identification. Third category introduces motivational drivers with negative correlation to the competitive and positive correlation to the cooperative personality traits such as job stability, work environment, and need of support.

Table 4

Correlation Matrix - Cooperative and Competitive Behavior vs. Motivational Drivers

\begin{tabular}{lccc}
\hline & Cooperative & Competitive & Difference of Correlation Coefficients \\
\hline Financial Reward & $-0.22^{*}$ & $0.08^{*}$ & -0.30 \\
Professional Challenge & $-0.21^{*}$ & $0.07^{*}$ & -0.28 \\
Appreciation of Work Performance & $-0.09^{*}$ & $0.08^{*}$ & -0.18 \\
Personal Development & $-0.11^{*}$ & $-0.06^{*}$ & -0.06 \\
Need of Structure & $-0.08^{*}$ & $-0.20^{*}$ & 0.12 \\
Job Mission Identification & 0.05 & $-0.21^{*}$ & 0.26 \\
Job Stability & 0.05 & $-0.22^{*}$ & 0.27 \\
Work Environment & $0.17^{*}$ & $-0.20^{*}$ & 0.37 \\
Need of Support & $0.31^{*}$ & $-0.24^{*}$ & 0.55 \\
\hline
\end{tabular}

Note. Source: Authors. The data was sorted according to differences of correlation coefficients. ${ }^{*} \mathrm{p}$-value $>0.05$.

Job mission identification and job stability have similar rate of correlation coefficients with both personality traits; however, a closer look at the graphical analysis in Figure 4 shows that job mission identification does not create a significant pattern in line with the competitive and/or cooperative behavior. On the other hand, job stability (Figure 5) creates a strong pattern where people with high cooperativity and low competitiveness profile have strong preference of the job stability motivational driver.

\section{Graphical Analysis}

The objective of this section is to illustrate interconnections between the three variables, notably competitive and cooperative variables and a respective personal motivational driver. The data on the type of behavior spread across the scale from one to ten, where values from one to five represent negative position on the scale of the given variable (one is extremely low value) and values from six to ten represent positive position (ten is extremely high value). A combination of three-dimensional graphs was used to present data in more comprehensive way in line with the following scheme (see Table 5). Axis $x$ and axis yin of the graph represent cooperativeness and competitiveness. The graph is thus divided into four quadrants with high and low competitiveness and high and low cooperativeness.

Table 5

Scheme for Displaying the Three-Dimensional Data

\begin{tabular}{lccc}
\hline \multirow{2}{*}{ Specific motivational driver, represented by color (axis z) } & \multicolumn{2}{c}{ Cooperativeness (axis x) } \\
\cline { 2 - 3 } & & Value on scale 1-5 & Value on scale 6-10 \\
\hline \multirow{2}{*}{ Competitiveness (axis y) } & Value 6-10 & High competitiveness & High competitiveness \\
& & Low cooperativeness & High cooperativeness \\
& Value 1-5 & Low competitiveness & Low competitiveness \\
& & Low cooperativeness & High cooperativeness \\
\hline
\end{tabular}


Specific motivational driver is displayed on the axis $\mathrm{z}$ by the intensity of the color; highest values of the motivational driver are represented by the darker red color, low values of the motivational drivers are represented by the green color, values in the middle of spectrum are represented by yellow color.

Figures 3, 4, and 5 reveal the relation between particular motivational driver and cooperativeness and competitiveness. The pattern is especially distinct in cases where the value of the difference between the correlation coefficient is higher.

Figure 3 illustrates the case where motivational drivers create positive correlation with the competitive behavior and negative correlation with the cooperative behavior. In other words, the following three motivational factors, namely financial reward, professional challenge, and appreciation of work performance have high importance for the competitive people; on the other hand, these factors do not represent a strong motivator for the people oriented cooperatively. The negative exponentially-weighted fitting was used to depict the exact distribution of values at the axis $\mathrm{z}$.
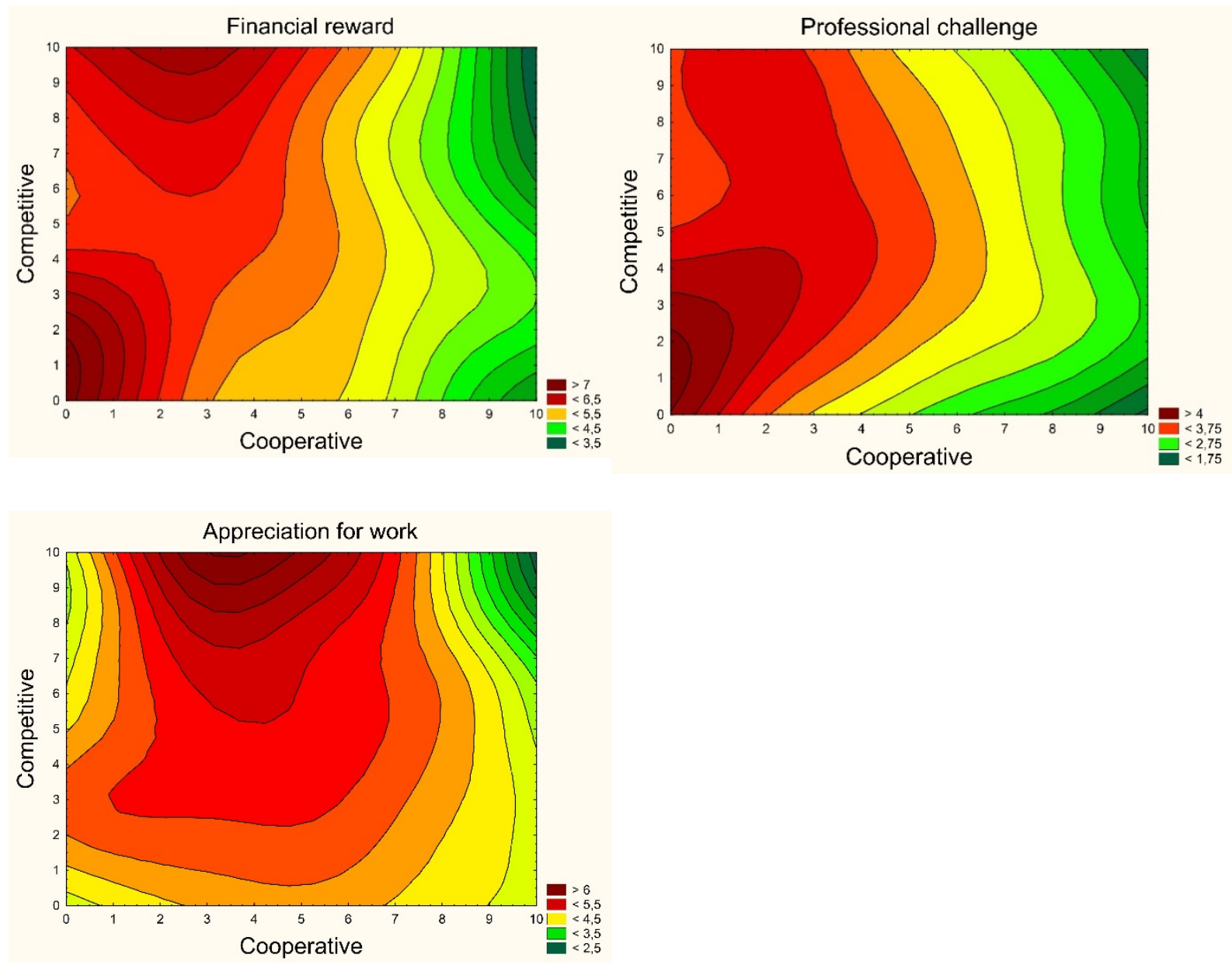

Figure 3.Three-dimensional graphs: Motivational drivers with positive correlation to the competitive and negative correlation to the cooperative personality traits

Note. Source: Authors. Statistical method used for graphical image - negative exponential adjustment.

Regarding the financial reward, there is a strong empirical expectation that the financial reward generates motivation. Garbers and Konradt (2014) enacted a meta-analysis of 146 
studies concluding that the financial rewards result in higher performance like individual incentives and team-based financial incentives. Beersema et al. (2003) in an experiment of 75 teams indicated that competitively oriented financial incentive increases speed and cooperatively oriented incentive increases accuracy.

The results of our study showed that the motivation by financial incentives is not decisive for the people who are oriented cooperatively. On the other hand, competitively oriented people prefer financial reward as a motivational driver. Similarly, appreciation or recognition for work and professional challenge are more important for people who have competitive orientation and are not primarily cooperative.

Figure 4 presents the motivational drivers which are not directly connected to any of the personality traits. Data on motivational preferences (personal development, need of structure, and job mission identification) do not correlate directly with the personality traits. The motivational drivers in Figure 4 do not create a graphically distinct maximum and are more or less dispersed along the field of competitive and cooperative behavior. That is why the linear graphical method was used to create the three-dimensional surface graphs.
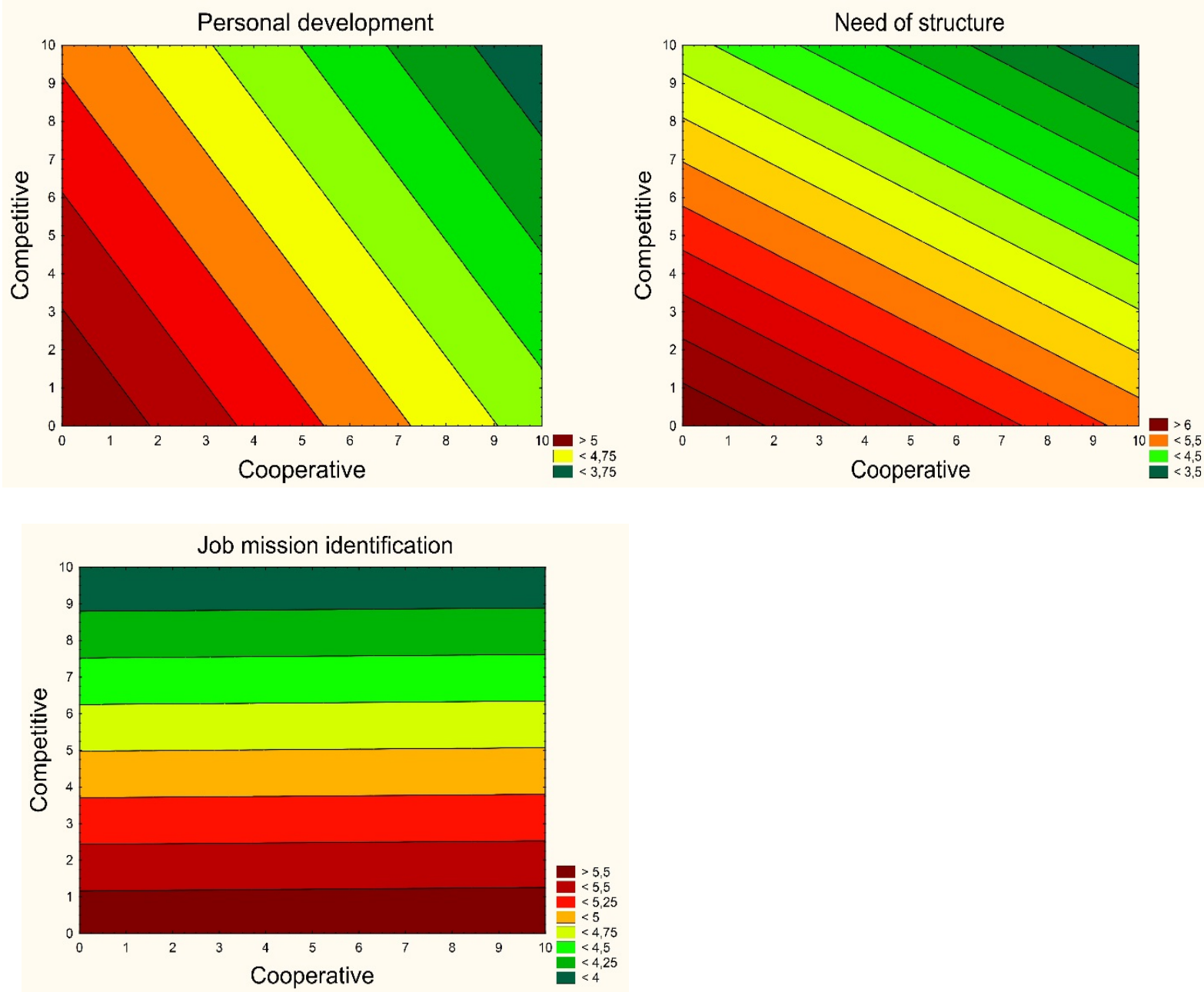

Figure 4. Three-dimensional graphs: Motivational drivers with no or negative correlation with the both personality traits - competitive and cooperative personality traits

Note. Source: Authors. Statistical method used for graphical image - linear three-dimensional surface graph. 
Figure 5 represents the motivational drivers which correlate positively with the cooperativeness and negatively with the competitiveness. The method of negative exponentially-weighted fitting was used for these variables, similarly as in Figure 4. Motivational drivers, job stability, quality of work environment and a need of support generate graphically distinct maximum in the quadrant of high cooperativeness and low competitiveness.
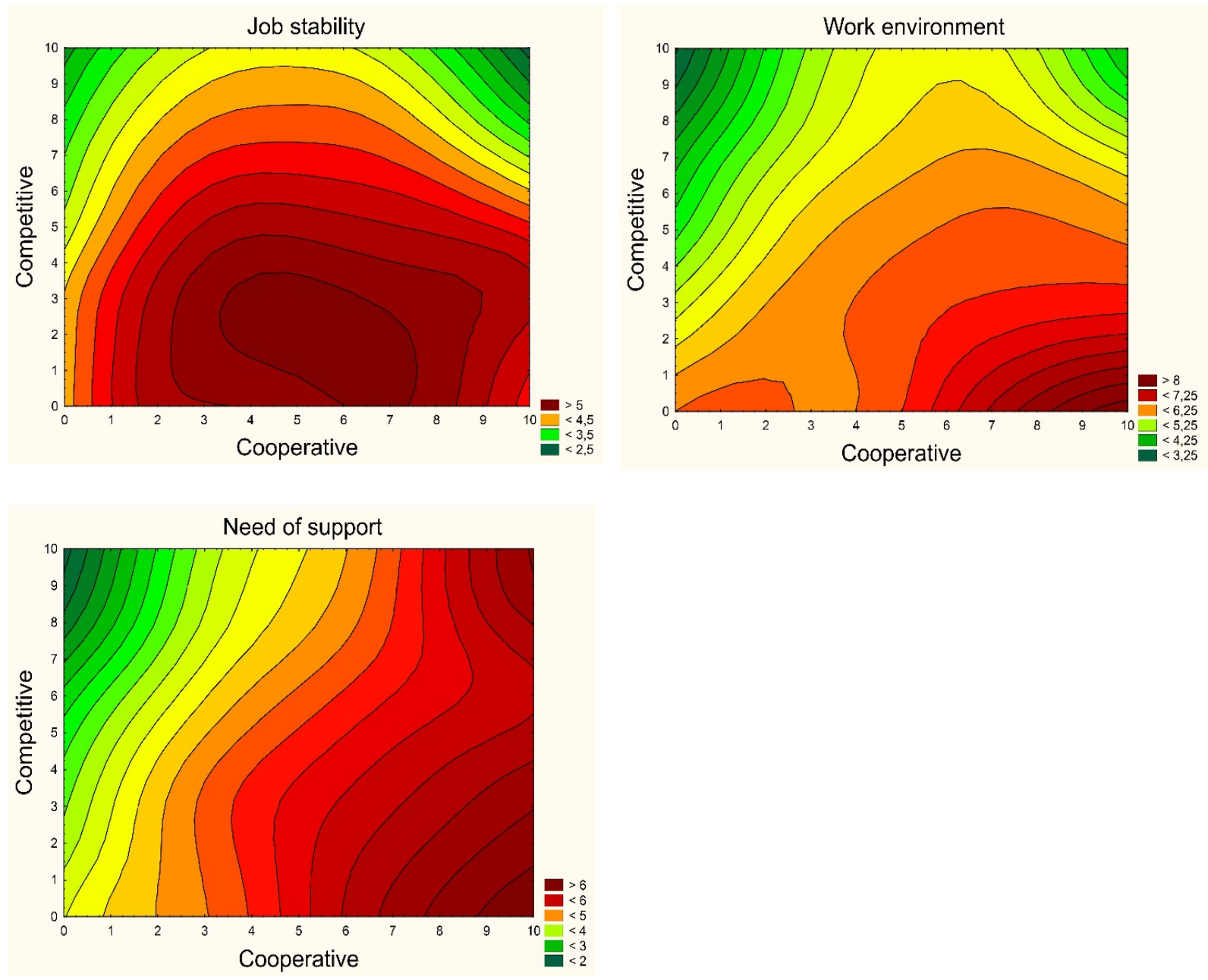

Figure 5. Three-dimensional graphs: Motivational drivers with negative correlation to the competitive and positive correlation to the cooperative personality traits

Note. Source: Authors. Statistical method used for graphical image - negative exponential adjustment.

These findings correspond with empirical expectations: Job stability, need of support and the quality of work environment represent motivators for highly cooperative people; competitive people do not find these drivers as a primer motivation. These findings revealed that there is no single universal motivational driver which would motivate competitive and cooperative personality at the same time. 


\section{Discussion and Conclusion}

Interestingly, authors have not found motivational drivers which would show strong correlations for both personality traits. Hence, it appears there is not a straightforward possibility how to motivate people who are both competitive and cooperative by single motivational factor having the same efficiency. If an organization wants to satisfy the complexity of motivational drivers of such a person, it needs to boost both aspects, namely competitive and cooperative.

Having searched the global academic resources as the Web of Science, Science Direct, or EBSCO, authors have come to conclusion that this type of research analyzing complex interrelations of motivational drivers and personality traits is not common. To this end, our approach can be perceived innovative in several aspects owing to the practical implications in organizations.

However, further research is needed, especially the type of research which would confirm that the hereby presented theoretical suggestions for the optimization of motivational management have real effects on work performance in organizations.

Conducted research brings an interesting insight into the interconnection between the motivational drivers and personality traits. The effort to map the specificity of motivational drivers represents a contribution to the optimization of the talent management in the frame of a modern HR management.

Conducted research has opened an innovative insight on the personality, as regards competitive and cooperative orientations which, nowadays, is a new phenomenon in organizations. Competitive personalities will be motivated by the motivational factors such as financial reward, professional challenge or appreciation of work performance. Following this, cooperative personalities will be motivated by the motivational drivers such as job stability, quality of work environment, and the need of support. The current paper is expected to have practical didactic implications for the management of human resources and improvement of the motivational and talent management system in organizations.

\section{References}

Ambrozová, E., Koleňák, J., Ullrich, D., \& Pokorný, V. (2016). Effectiveness of competent decision making of professional managers in the context of the modern corporate environment and its requirements for the quality of their skills. Proceedings of the 9th International Conference European Entrepreneurship Forum 2015: Efficiency in the Private and the Public Sector, 5-22.

Beersma, B., Hollenbeck, J. R., Humphrey, S. E., Moon, H., Conlon, D. E., \& Ilgen, D. R. (2003). Cooperation, competition, and team performance: Toward a contingency approach. Academy of Management Journal, 46(5), 572-590.

Garbers, Y., \& Konradt, U. (2014). The effect of financial incentives on performance: A quantitative review of individual and team-based financial incentives. Journal of occupational and organizational psychology, 87(1), 102-137.

Greenwald, A. G., \& Banaji, M. R. (1995). Implicit social cognition: Attitudes, self-esteem, and stereotypes. Psychological Review, 102, 4-27.

Kolařová, I., \& Žiaran, P. (2016). Competitive vs. cooperative personality, what is the Difference? Implications for the personnel selections. Procedia-Social and Behavioral Sciences, 220, 184-190.

Meglino, B.M., \& Ravlin, E.C. (1998). Individual values in organizations: Concepts, controversies, and research. Journal of Management, 24, 351-390.

Meyer, J. P., Becker, T. E., \& Vandenberghe, C. (2004). Employee commitment and motivation: A conceptual analysis and integrative model. Journal of Applied Psychology, 89(6), 991-1007.

Pinder, C. C. (1998). Motivation in work organizations. Upper Saddle River, NJ: Prentice Hall. 
Steel, R. P., \& Rentsch, J. R. (1997). The dispositional model of job attitudes revisited. Journal of Applied Psychology, 82, 873-879.

Webb, E., Perry, M., \& Fennelly, L. J. (2015). Employee motivation theory and application. In Davies, S. J.(Eds.), Security Supervision and Management: Theory and Practice of Asset Protection. Netherland: Elsevier.

Žiaran, P., Janiš, V., \& Pánková, B. (2016). Understanding the nature of the motivational driver "professional challenge"-a way towards higher efficiency in personnel selection. Proceedings of the 9th International Conference European Entrepreneurship Forum 2015: Efficiency in the Private and the Public Sector, 181-189. 